REVIEW

\title{
Recommended evaluation of adrenal incidentalomas is costly, has high false-positive rates and confers a risk of fatal cancer that is similar to the risk of the adrenal lesion becoming malignant; time for a rethink?
}

\author{
T J Cawood, P J Hunt, D O'Shea ${ }^{1}$, D Cole and S Soule \\ Department of Endocrinology, Christchurch Hospital, Private Bag 4710, Christchurch, New Zealand and ${ }^{1}$ Department of Endocrinology, St Vincent's \\ University Hospital, Dublin, Ireland
}

(Correspondence should be addressed to T J Cawood; Email: tom.cawood@cdhb.govt.nz)

\begin{abstract}
Objective: To assess the performance of current clinical recommendations for the evaluation of an adrenal incidentaloma.

Design and methods: Literature review. Electronic databases (Pubmed, Ovid and citation searches from key articles) from 1980 to 2008 were searched. Eligible studies were those deemed most applicable to the clinical scenario of a patient referred to an endocrinologist for assessment of an incidentally detected adrenal mass. Surgical series, histopathological series and oncological series were reviewed and most were excluded.

Results: The prevalence of functional and malignant lesions presenting as adrenal incidentaloma was similar to that quoted in most reviews, other than a lower incidence of adrenal carcinoma (1.9 vs $4.7 \%$ ) and metastases (0.7 vs 2.3\%). The development of functionality or malignancy during follow-up was rare $(<1 \%$ becoming functional and $0.2 \%$ becoming malignant). During follow-up, false-positive rates of the recommended investigations are typically 50 times greater than true positive rates. The average recommended computed tomography (CT) scan follow-up exposes each patient to $23 \mathrm{mSv}$ of ionising radiation, equating to a 1 in 430 to 2170 chance of causing fatal cancer. This is similar to the chance of developing adrenal malignancy during 3-year follow-up of adrenal incidentaloma.

Conclusion: Current recommendations for evaluation of adrenal incidentaloma are likely to result in significant costs, both financial and emotional, due to high false-positive rates. The dose of radiation involved in currently recommended CT scan follow-up confers a risk of fatal cancer that is similar to the risk of the adrenal becoming malignant. This argues for a review of current guidelines.
\end{abstract}

European Journal of Endocrinology $161513-527$

\section{Introduction}

The scenario of a patient being referred to an endocrinologist for assessment of an adrenal incidentaloma is becoming increasingly common, with improvements in imaging, increasing numbers of radiological investigations and an aging western world population. Current clinical management of such patients varies across different centres and countries, as there is a relative lack of prospective outcome data on which to base clinical recommendations, with practice generally led by consensus (1) and expert opinion (2). Current guidelines recommend various endocrine investigations and radiological imaging at baseline. If the lesion is thought to be benign and non-functional, it is suggested that these tests are repeated at between 6 and 12 monthly intervals for between 2 and 4 years, which typically would include between one and three followup computed tomography (CT) scans (1-3).
While such an approach aims to avoid missing an important functional or malignant lesion, because of the low prevalence of such conditions, investigations need to have very high sensitivity and specificity in order to perform adequately in this environment. The consequence of low specificity is a high false-positive rate, which can result in significant financial and emotional cost, with the potential for further tests and/or unnecessary adrenalectomy. Furthermore, there has been little attention paid to the possible harmful consequences of these investigations, in particular the exposure to ionising radiation from repeated CT scanning.

In order to assess the performance of the current clinical recommendations, we first reviewed the literature to find the most representative data on the prevalence of the various different pathologies that are likely to present as an adrenal incidentaloma. This involved excluding those studies that may bias towards 
malignant or functional lesions, such as surgical, histopathological and oncology series.

We then reviewed the performance of the various investigations commonly used for assessment of adrenal incidentalomas, and applied the sensitivity and specificity data to the likely prevalence of the different pathologies at both initial presentation and during follow-up. Finally, we considered the potential induction of fatal cancer as a result of exposure to ionising radiation during repeated $\mathrm{CT}$ scanning.

\section{Design and methods}

A literature review was undertaken that was intended to include studies that were most applicable to the clinical scenario of a patient referred to an endocrinologist for assessment of an incidentally detected adrenal mass. Electronic databases (Pubmed and Ovid) from 1980 to 2008 were searched, and additional citations from key articles were also included. Pre-determined exclusion criteria were surgical series, histopathological series and oncological series, non-English studies (where inclusion criteria could not be accurately determined), studies where a proportion of the patients from larger multicentre studies may have been reported elsewhere, studies where the study population was not $>20$ and studies where the study population was neither a random sample nor a consecutive series.

Using the search terms 'adrenal' + 'incidentaloma' and 'adrenal' + 'incidental', from 1980 to 2008, 828 studies were found. After selecting those articles pertaining to the presentation or follow-up of adrenal incidentaloma, and only those written in English and where $n>20$, there were 68 articles remaining. To these articles were added a further 42 studies that were obtained from citation searches from two leading reviews $(4,5)$, giving a total of 110 articles. A number of these were then excluded for a variety of reasons including review articles (28), surgical series (21), studies where a proportion of the patients from larger multicentre studies may have been reported elsewhere (15) and studies including oncology patients (7) (Fig. 1). A small number of additional exclusion criteria were applied where methodological issues were such that these studies were not deemed most applicable to the clinical scenario of adrenal incidentaloma. Examples of such exclusions are given below.

\section{Prevalence of malignant and functional lesions in adrenal incidentaloma}

The prevalence of malignant and functional lesions in true adrenal incidentaloma is likely to have been overestimated in the literature for a variety of reasons. The consensus definition of a true adrenal incidentaloma is an adrenal mass $(>1 \mathrm{~cm}$ diameter) detected incidentally during imaging performed for extraadrenal complaints (therefore excluding those with severe or paroxysmal hypertension, hypokalaemia, clinical signs of hypercortisolism or hyperandrogenism). Also, those patients with a history of previous or current malignancy, who represent a group of patients with an increased risk of harbouring an adrenal metastasis, should arguably be referred to an oncology service and excluded from consideration of true incidentalomas. The operating characteristics of investigation algorithms intended to reasonably exclude a functional or malignant lesion in those with a low pretest probability of malignancy may not be adequate in this patient group.

A number of studies should be excluded from consideration if the aim is to determine the likely prevalence of malignant and functional lesions in those presenting to endocrinologists as a true incidentaloma. Such studies include reports where some or all of the patients are from surgical series (6-12). These lesions have been deemed worthy of consideration for surgical removal, usually due to being larger or more suspicious of malignancy. These data are likely to overestimate the prevalence of malignancy compared with those referred to endocrinology with true adrenal incidentaloma (13). Also, a number of papers have been misrepresented in literature reviews (4), where the percentage of malignant lesions is reported as a percentage of those operated on, rather than as a percentage of those initially assessed with an incidentaloma, again exaggerating the prevalence of malignant lesions (e.g. $13 \%$ of those operated on versus $6 \%$ of the total (14), $14 \%$ of those operated upon versus 3\% of total (15) and 12\% in those operated upon versus $2.6 \%$ of total (16)). Other sources of potential bias include studies involving patients with a history, current diagnosis or suspicion of malignancy (16-20), as well as studies where the adrenal lesion is not incidental, but was detected during investigations based on symptoms, signs, hormone levels and imaging studies (21). Additional problems include studies where those with non-functional adrenal masses are excluded (8), studies where the primary imaging modality was ultrasound (and so smaller lesions that are more likely to be benign may be missed) (22) and studies that excluded patients with masses smaller than $2 \mathrm{~cm}$ in diameter (23). Further problems arise when including studies of selected patients rather than random or consecutive series (24), including studies of small size which are consequently more influenced by random variation (e.g. where a single case can alter reported prevalence by $5 \%(8,17,25))$, and also studies where a proportion of the patients from larger multicentre studies may have previously been reported elsewhere in smaller reports involving less centres, so potentially over-representing any random biases (26-34). More recent papers, not yet established in review literature, also have potential sources of bias such as excluding lesions that appear 


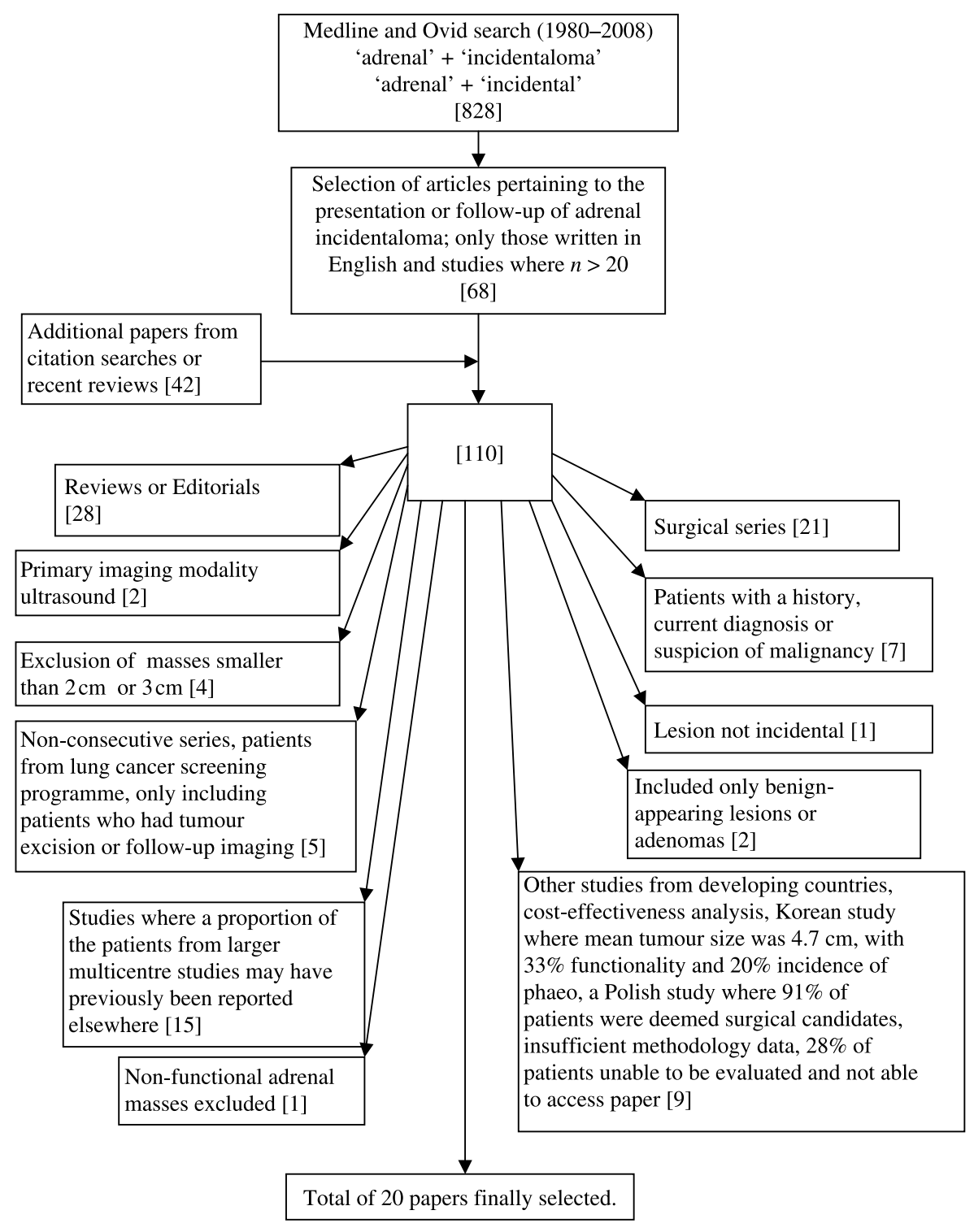

Figure 1 Inclusion and exclusion criteria for selection of studies. At presentation, nine studies were included (19, 30, 34, 36-42). At follow-up, 14 studies were included $(19,23,33,35,36,39,41,43-49)$. Four papers were included despite various methodological issues (19, 23, 35, 47). These included a study that included oncology patients, where the oncology patients were excluded in the assessment of presentation prevalence, but were included in assessment of follow-up and where one oncology patient developed an adrenal metastases (19). This may have led to an overestimate of the chance of developing adrenal metastases in adrenal incidentaloma follow-up. The other papers were used in the assessment of follow-up and included a study where only benignappearing lesions or adenomas $(23,35)$ were followed, or where only lesions $>2 \mathrm{~cm}$ were followed (47), with these issues likely to have a negative $(23,35)$ and a positive (47) influence on the chance of developing functional or malignant lesions respectively. The authors considered that with the relative lack of follow-up studies, even with these methodological issues, these articles had sufficient merit to justify their inclusion. benign (Hounsfield units $(\mathrm{HU})<10$ ) or patients with a specific CT diagnosis such as haematoma and myelolipoma (35).

In short, the most relevant studies for the scenario of true adrenal incidentaloma report on consecutive or unselected patients and exclude patients with a history of previous or current malignancy. In addition, where a larger multicentre report includes patients that may already have been described in smaller single-centre studies, only the larger report should be considered. Using these criteria and others detailed above, we consider the studies in Table 1 to be the most relevant (30, 34, 36-42), plus one study where we have excluded the oncology patients (19).

From these studies, the expected prevalence of primary adrenal cancer in true adrenal incidentaloma is less than half that quoted in recent extensive literature reviews $(2,4,5)$ (mean $1.9 \%$, median $1.4 \%$, compared to mean 4.4-4.7\%, (Table 2)). Similarly, when compared with earlier inclusive reviews, these selected studies find the prevalence of metastasis is less than half (mean $0.7 \%$, median $0.2 \%$, compared to mean $2.3 \%$ ), the prevalence of phaeochromocytoma is two thirds (mean 3.1\% compared to $5.2 \%$ ), the prevalence of aldosteronoma is half (mean $0.6 \%$ compared to $1.1 \%$ ), while the prevalence of subclinical Cushing's syndrome is similar (mean 6.4\%, median $6.0 \%$, compared to mean $6.6 \%$ ).

Therefore, by including surgical series and the other above-listed biases, the current literature leads to a significant overestimate of the chance of a true adrenal incidentaloma being either malignant or 


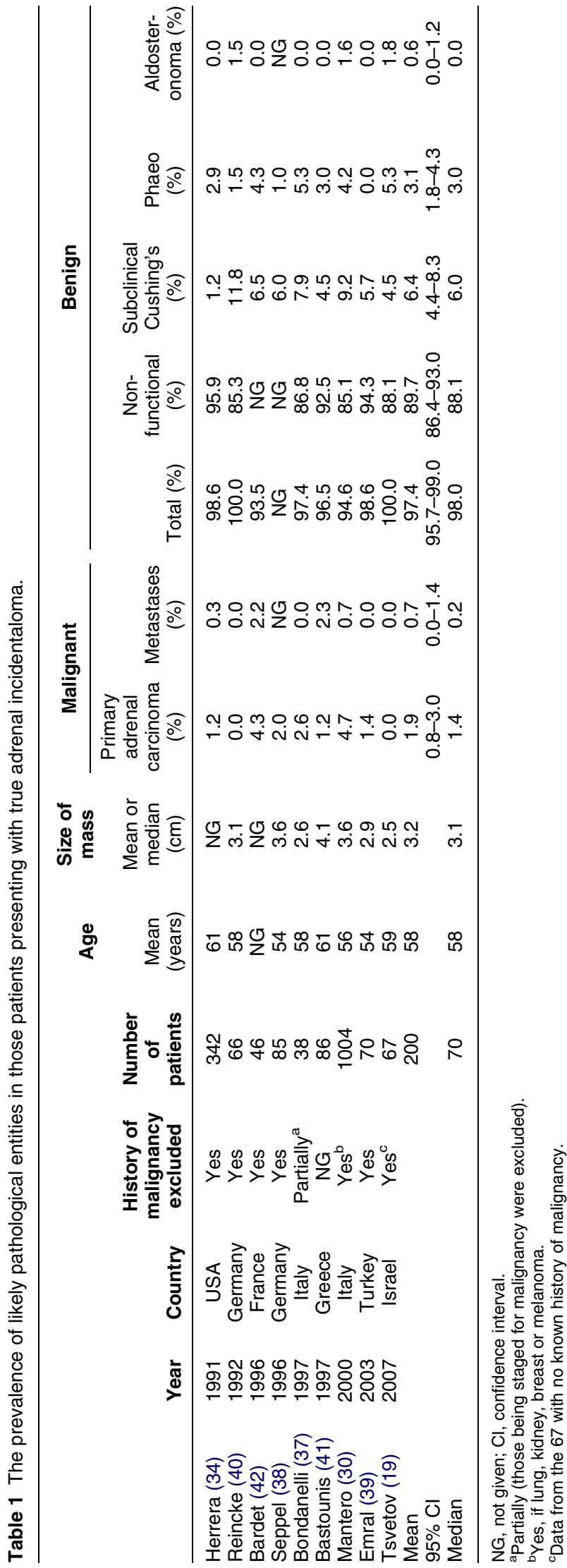

functional, with the exception of subclinical Cushing's syndrome. With this lower pre-test probability of disease, the investigation algorithms based on the higher prevalence rates may be suboptimal for managing true adrenal incidentaloma. Furthermore, as CT technology has improved in the last two decades, the ability to detect smaller lesions is improving, and so the proportion of smaller, more likely benign lesions that are detected is likely to be increasing. This is supported by the negative correlation $(R=-0.4$, $R^{2}=0.16$ ) between the year of study and mean tumour size in the studies listed in Table 1 . Therefore, even the lower prevalence estimates derived from the studies in Table 1 may be an overestimate when considering the population of patients now referred with adrenal incidentaloma, which may include an increasing proportion of patients with smaller adrenal masses.

There are no data giving an accurate figure for the prevalence of adenomas among adrenal incidentalomas. This is relevant because the performance of CT scanning in assessing adrenal lesions is partly related to its ability to identify lipid-rich lesions including adenoma by incorporating HU into diagnostic algorithms. Adenomas may be non-functional, but also include lesions causing subclinical Cushing's syndrome and hyperaldosteronism (HA). Adenomas may be under-represented among surgical series as the majority of small, benign, non-functional lesions will be adenomas and hence less likely to be surgically excised. Estimates of the prevalence of adrenal adenomas among adrenal incidentalomas vary. One study suggests a prevalence of $52 \%$ (4), although this review does include a number of surgical series. The real prevalence of adenomas is likely to be nearer $80 \%$, this being the total of apparently non-functioning adenomas $(71.2 \%)$, plus lesions causing subclinical Cushing's syndrome $(7.9 \%)$ and lesions causing HA $(1.2 \%)(5)$.

\section{Follow-up of adrenal incidentalomas}

Studies addressing the follow-up of adrenal incidentaloma are relatively low in number and have a considerable degree of heterogeneity. The inclusion of adrenal incidentaloma studies where the adrenalectomy rate is $100 \%$ would help to provide more accurate histological data and reduce the chance of underdiagnosis, but such a study would be unethical, with the general experience being that relatively few patients develop malignancy or clinically apparent functional lesions. Mindful of these and other limitations, we consider the studies included in Table $3(19,23,33,35$, $36,39,41,43-49)$ to be those most relevant when considering the natural history of adrenal incidentalomas that are initially considered benign and non-functioning. 


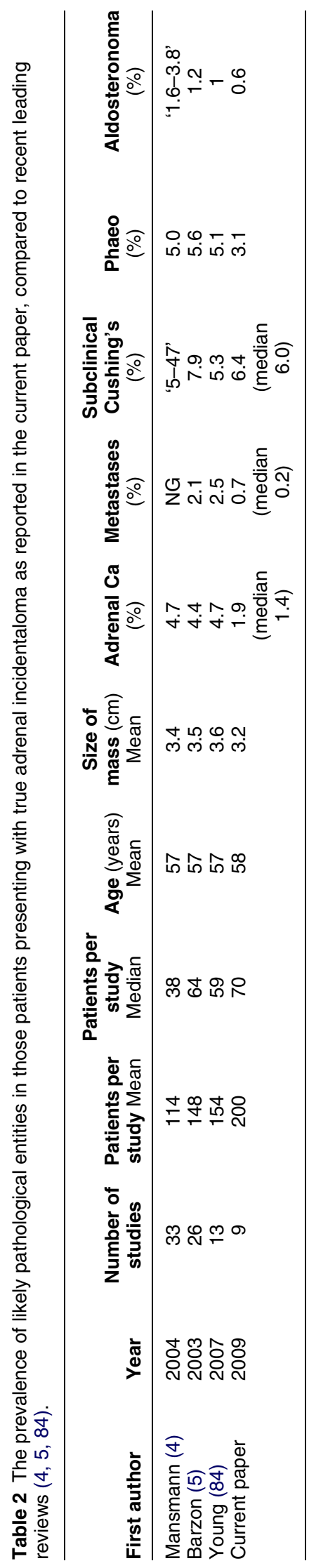

For any test proposed for follow-up of adrenal incidentalomas, the following should be considered: i) what is the sensitivity and specificity of the test, particularly in the low-prevalence situation of adrenal incidentaloma follow-up, ii) what is the consequence of false-negative and false-positive results, iii) are there any risks associated with the test and iv) what are the financial costs of the test?

\section{Tests for subclinical Cushing's syndrome}

Subclinical Cushing's syndrome has not been adequately defined, and the natural history of this syndrome is unknown (4). The definitions of subclinical Cushing's syndrome vary widely in the literature. No current test or definition accurately identifies those at risk of complications (such as glucose intolerance, obesity, osteoporosis and adrenal failure following adrenalectomy). Current definitions of subclinical Cushing's syndrome include autonomous cortisol secretion in patients who do not have the typical signs and symptoms of hypercortisolism (2). Others use definitions that stipulate the absence of clinical signs of cortisol excess plus at least two biochemical abnormalities of the hypothalamic-pituitary-adrenal (HPA) axis $(30,50)$. The main drawback of these definitions is that the more tests that are performed looking for HPA abnormalities, the higher the rate of diagnosis of subclinical Cushing's syndrome. Furthermore, if the disease is defined by laboratory abnormalities, rather than by some clinical correlate, it becomes difficult to define false positives, as all positives are by definition indicative of the diagnosis.

The absence of an agreed definition of subclinical Cushing's syndrome or gold standard test for diagnosing subclinical Cushing's syndrome makes the determination of specificity and sensitivity of tests used to diagnose subclinical Cushing's syndrome problematic. The NIH position statement (2) and others including the Endocrine Society (51) recommend using the $1 \mathrm{mg}$ dexamethasone (DXT) as the initial test for subclinical Cushing's syndrome. Applying the commonly used definition of subclinical Cushing's syndrome (the absence of clinical signs of cortisol excess, plus two or more abnormalities of basal or dynamic test of the HPA axis), the largest study is from Mantero et al. (30) comprising 946 adrenal incidentalomas, and 854 were characterised as non-hypersecreting and 92 as subclinical Cushing's syndrome. Tests used to evaluate the HPA axis included urinary-free cortisol (UFC), plasma ACTH, serum DHEA sulphate (DHEAS), serum 17-hydroxyprogesterone (17-OHP), 24-h cortisol rhythm, $1 \mathrm{mg}$ DXT, $100 \mu \mathrm{g}$ CRH test and $250 \mu \mathrm{g}$ ACTH test, although not all tests were performed on all patients.

The results (Table 4 ) indicate that $\sim 15 \%$ of lesions classified as non-hypersecreting demonstrate a single abnormal test of the HPA axis, a significantly lower 
Table 3 Studies detailing the follow-up of adrenal incidentalomas thought to be benign and non-functioning after initial diagnostic work-up.

\begin{tabular}{|c|c|c|c|c|c|c|c|c|c|c|c|c|c|c|c|c|c|}
\hline First author & Year & $\begin{array}{l}\text { Number } \\
\text { of } \\
\text { patients } \\
(n>20)\end{array}$ & $\begin{array}{c}\text { Mean } \\
\text { age } \\
\text { (years) }\end{array}$ & $\begin{array}{c}\text { Size of } \\
\text { masses } \\
\text { (mean or } \\
\text { median) }\end{array}$ & $\begin{array}{l}\text { Follow- } \\
\text { up } \\
\text { duration } \\
\text { (years) }\end{array}$ & $\begin{array}{l}\text { Increased } \\
\text { in size } \\
(\%)\end{array}$ & $\begin{array}{l}\text { Unchanged } \\
\text { in size } \\
(\%)\end{array}$ & $\begin{array}{l}\text { Decreased } \\
\text { in size } \\
(\%)\end{array}$ & $\begin{array}{c}\text { Became } \\
\text { malignant } \\
(\%)\end{array}$ & $\begin{array}{l}\text { Developed } \\
\text { adrenal } \\
\text { Ca }(\%)\end{array}$ & $\begin{array}{l}\text { Developed } \\
\text { metastases } \\
(\%)\end{array}$ & $\begin{array}{c}\text { Benign } \\
(\%)\end{array}$ & $\begin{array}{c}\text { Became } \\
\text { functional } \\
(\%)\end{array}$ & $\begin{array}{c}\text { Developed } \\
\text { Cushing's } \\
\text { syndrome } \\
\text { (\%) }\end{array}$ & $\begin{array}{c}\text { Developed } \\
\text { subclinical } \\
\text { Cushing's } \\
\text { syndrome } \\
(\%)\end{array}$ & $\begin{array}{l}\text { Developed } \\
\text { phaeochro- } \\
\text { mocytoma } \\
(\%)\end{array}$ & $\begin{array}{l}\text { Developed } \\
\text { aldoster- } \\
\text { onoma (\%) }\end{array}$ \\
\hline Song (35) & 2007 & 71 & $N G$ & $N G$ & 2.7 & 0.0 & NG & NG & 0 & 0 & 0 & 100 & $N G$ & NG & $N G$ & NG & NG \\
\hline Song (35) & 2007 & 209 & NG & NG & NG & NG & NG & $N G$ & 0 & 0 & 0 & 100 & NG & NG & NG & 1 & NG \\
\hline Song (35) & 2007 & 41 & NG & NG & 3.3 & $N G$ & $N G$ & $N G$ & 0 & 0 & 0 & 100 & $N G$ & NG & $N G$ & NG & NG \\
\hline Favia (23) & 2000 & 90 & NG & NG & 1.8 & $N G$ & NG & NG & 0 & 0 & 0 & 100 & 0 & 0 & 0 & 0 & 0 \\
\hline Barzon (43) & 1999 & 75 & 56 & 2.5 & 4.0 & 16.0 & 81.0 & 2.7 & 0 & 0 & 0 & 100 & 8 & 2.7 & $4^{\mathrm{a}}$ & 1.3 & 0 \\
\hline Bulow (44) & 2006 & 229 & 64 & 2.5 & 2.1 & 7.4 & 87.4 & 5.2 & 0 & 0 & 0 & 100 & 2.6 & 1.3 & 0 & 0.7 & 0 \\
\hline Tsvetov (19) & 2007 & 88 & NG & 2.6 & 2.0 & 12.5 & 87.5 & 0.0 & 1.1 & 0 & $1.1^{\mathrm{b}}$ & 98.9 & 0 & 0 & 0 & 0 & 0 \\
\hline Barry (33) & 1998 & 231 & 64 & 2.0 & 7.0 & 4.0 & 96.0 & 0.0 & 0 & 0 & 0 & 100 & 0 & 0 & 0 & 0 & 0 \\
\hline Libe (45) & 2002 & 64 & 61 & 2.5 & 2.1 & 20.0 & 0.0 & 0.0 & $1.6^{\mathrm{c}}$ & 0 & 0 & 98.4 & 0 & 0 & 0 & 0 & 0 \\
\hline Siren (46) & 2000 & 27 & 59 & 2.5 & 7.1 & 25.0 & 31.0 & 44.0 & 0 & 0 & 0 & 100 & 0 & 0 & 0 & 0 & 0 \\
\hline Rossi (36) & 2000 & 32 & NG & NG & 2.8 & 15.6 & 84.6 & 0.0 & 0 & 0 & 0 & 100 & 0 & 0 & 0 & 0 & 0 \\
\hline Bastounis (41) & 1997 & 60 & $N G$ & 3.2 & 3.6 & 3.7 & 97.3 & 0.0 & 0 & 0 & 0 & 100 & NG & 0 & $N G$ & $N G$ & $N G$ \\
\hline $\begin{array}{l}\text { Grossrubatscher } \\
\text { (47) }\end{array}$ & 2001 & 53 & $N G$ & 2.5 & 2.0 & 41.5 & 47.2 & 11.3 & 0 & 0 & 0 & 100 & 0 & 0 & 0 & 0 & 0 \\
\hline Emral (39) & 2003 & 60 & NG & $N G$ & 2.0 & 0.0 & NG & $N G$ & 0 & 0 & 0 & 100 & 0 & 0 & 0 & 0 & 0 \\
\hline Mantero (49) & 2000 & 53 & $N G$ & $N G$ & $>1$ & 26.4 & $N G$ & $N G$ & 0 & 0 & 0 & 100 & 0 & 0 & 0 & 0 & 0 \\
\hline Bencsik (48) & 1995 & 27 & NG & $<3$ & 1.8 & 3.7 & NG & $N G$ & 0 & 0 & 0 & 100 & 0 & 0 & 0 & 0 & 0 \\
\hline Mean & & 83.8 & 60.8 & 2.5 & 3.2 & 14.7 & 68.0 & 7.0 & 0.2 & 0.0 & 0.1 & 99.8 & 0.9 & 0.3 & 0.3 & 0.2 & 0.0 \\
\hline $95 \% \mathrm{Cl}$ & & & & & & $8.0-21.3$ & $45.8-90.2$ & $-2.4-16.4$ & $0.0-0.4$ & $0.0-0.0$ & $0.0-0.2$ & $\begin{array}{r}99.6- \\
100.0\end{array}$ & $-0.5-2.2$ & $-0.1-0.7$ & $-0.4-1.0$ & $-0.1-0.4$ & $0.0-0.0$ \\
\hline Median & & 60.0 & 61.0 & 2.5 & 2.1 & 14.1 & 84.6 & 0.0 & 0.0 & 0.0 & 0.0 & 100.0 & 0.0 & 0.0 & 0.0 & 0.0 & 0.0 \\
\hline
\end{tabular}

$\mathrm{NG}$, not given; $\mathrm{Cl}$, confidence interval.

These patients had any abnormal baseline hormonal test repeated, plus up to eight hormonal assessments in total, including $0800 \mathrm{~h}$ cortisol, $1800 \mathrm{~h}$ cortisol, morning ACTH, DHEAS, $17-\mathrm{OHP}, 1 \mathrm{mg}$ DXT and in some cases CRH test. The paper by Song is included three times, as these subgroups of patients were followed up either radiologically (71 patients), by histology or imaging (209 patients), or by clinical

Represents one case of renal cell cancer metastasis in a patient with a known history of renal cell carcinoma; arguably this study should have been excluded from this analysis.

'Represents one case of adrenal non-Hodgkin's lymphoma. 
Table 4 Hormonal evaluation of non-hypersecreting adrenal incidentalomas and lesions characterised as causing subclinical Cushing's syndrome, from Mantero (30).

\begin{tabular}{lll}
\hline & $\begin{array}{l}\text { Non- } \\
\text { hypersecreting } \\
(\%)\end{array}$ & $\begin{array}{l}\text { Subclinical } \\
\text { Cushing's } \\
\text { syndrome (\%) }\end{array}$ \\
Test & 15 & 79 \\
\hline Low morning ACTH levels & 11 & 75 \\
$\begin{array}{l}\text { Above normal UFC } \\
\text { Abnormal circadian rhythm } \\
\text { of plasma cortisol }\end{array}$ & 17 & 43 \\
$\begin{array}{l}\text { Blunted ACTH response } \\
\text { to CRH }\end{array}$ & 17 & 55 \\
$\begin{array}{l}\text { Cortisol not adequately } \\
\text { suppressed by 1 mg } \\
\text { dexamethasone }\end{array}$ & 10 & 73 \\
\hline
\end{tabular}

proportion than those classified as subclinical Cushing's syndrome. However, in the light of the current definition of subclinical Cushing's syndrome (requiring two or more abnormal tests of the HPA axis), it is relevant to note that even the use of two out of the three most frequently abnormal HPA tests would still fail to capture a significant proportion of patients otherwise labelled as subclinical Cushing's syndrome had more tests been performed. For example, an abnormal $1 \mathrm{mg}$ DXT test plus a low ACTH only identified $55 \%$ of those in the subclinical Cushing's syndrome group, and an abnormal $1 \mathrm{mg}$ DXT plus above-normal UFC only identified $50 \%$ of the subclinical Cushing's syndrome group. Therefore, a single $1 \mathrm{mg}$ DXT will label $10 \%$ of the nonhypersecretors as subclinical Cushing's syndrome $(10 \%$ false positive, specificity $90 \%$ ) and will fail to label $27 \%$ of the subclinical Cushing's syndrome group (27\% false negative, sensitivity $73 \%$ ). The cut-off for morning cortisol used in this study was $5 \mu \mathrm{g} / \mathrm{dl}(138 \mathrm{nmol} / \mathrm{l})$, and more stringent cut-offs would increase the falsepositive rate.

This $73 \%$ sensitivity of the $1 \mathrm{mg}$ DXT in subclinical Cushing's syndrome is lower than that found in other studies (92\% (45), 100\% (40), 86\% (52) and 83\% (53)), although these other studies were much smaller (6-12 patients, compared with 92 (30)). When taken together, the $1 \mathrm{mg}$ DXT was abnormal in $76 \%$ (110/131) (50) of those diagnosed with subclinical Cushing's syndrome. The $90 \%$ specificity is in agreement with other studies of subclinical Cushing's syndrome $(91 \%(2,54))$.

\section{Tests for phaeochromocytoma}

Recommendations for clinical practice from the First International Symposium on Pheochromocytoma are that measurement of plasma or urinary fractionated metanephrines should be the first-line test for diagnosis, and reference intervals should favour sensitivity over specificity (55).
Available studies are confounded by heterogeneity, examining different patient populations, with different pre-test probabilities, and using total or fractionated metanephrines, with different laboratory cut-offs. Despite these limitations, there is a reasonable degree of consistency with urinary metanephrines having median sensitivity of 95\% (77\% (56), 97.1\% (57), 90\% (58), 100\% (59), 100\% (60), 94.7\% (61) and 95\% (62)) and specificity of $95 \%$ (93\% (56), 91.1\% (57), 98\% (58), 94\% (59), 99.1\% (60), 95.3\% (61) and 98\% (62)). Plasma metanephrines have slightly higher sensitivity of 98\% (97\% (58), 99\% (56), 98\% (63), 100\% (64) and $96 \%(65))$, but lower specificity of $89 \%$ (85\% (58), $89 \%$ (56), 92\% (63), 96.7\% (64) and 80\% (65)).

\section{Tests for HA}

The recommended initial screening test for HA in hypertensive patients with adrenal incidentalomas is the ratio of ambulatory morning plasma aldosterone concentration to plasma renin activity (Aldos/PRA) $(2,4,13)$. Normokalaemic HA occurs at a frequency of $7-38 \%$, hence screening for HA should not be limited to those who are hypokalaemic (4). The ability of the Aldos/PRA to detect primary HA in resistant hypertension varies, depending on numerous factors including patient selection criteria, medication use and laboratory cut-offs. Typical expected performance of the Aldos/PRA is in the region of sensitivity $90 \%(78 \%$ (66), 89\% (67), 92\% (68), 90\% (69), 96\% (70) and $100 \%(71))$ and specificity $90 \%(83 \%(66), 84 \%(71)$, $85 \%$ (70), 91\% (69), 96\% (67) and 100\% (68)). There are less data on the performance of Aldos/PRA in the setting of adrenal incidentaloma, although studies that have retrospectively applied certain cut-offs have achieved sensitivity of $100 \%$ and specificity of 95,96 and $99 \%(72-74)$. However, these figures may significantly overestimate the true performance of the Aldos/PRA ratio as in the quoted series the prevalence of HA was remarkably high at $14 \%$ (73) and $12 \%$ (10 of the 50 incidentaloma patients) (74), when compared with the expected prevalence of $1 \%$ in all adrenal incidentaloma patients and $4 \%$ in hypertensive adrenal incidentaloma patients (72). Of note, the true sensitivity of the Aldos/PRA as a screening test in adrenal incidentaloma remains unclear, as without additional definitive tests such as saline suppression in patients with a normal Aldos/PRA ratio, the sensitivity of the ratio for the detection of HA in the hypertensive patient with an incidentaloma remains conjectural.

Taken together, the sensitivity and specificity of the Aldos/PRA for detecting HA in patients with hypertension and an adrenal incidentaloma are likely to be in the region of $90-100 \%$, depending on the cut-offs used and patient group studied, with a figure of $95 \%$ being arguably a reasonable estimate. 


\section{Imaging as a test for malignancy}

The ability of radiological imaging to detect malignant adrenal incidentalomas varies depending upon the criteria used. CT is generally better able to differentiate between adenomas and non-adenomatous lesions, compared with its ability to diagnose or exclude specific pathological entities.

When selecting CT criteria that discriminate between adenomatous and other lesions, the majority of studies have determined thresholds for parameters such as $\mathrm{HU}$ in a retrospective manner. These thresholds are likely to perform less well when tested prospectively. Only a minority of studies (75) have prospectively evaluated the performance of $\mathrm{HU}$ thresholds obtained from CT adrenals, and derived a sensitivity of $71 \%$ and specificity of $100 \%$ for diagnosing adrenal adenomas. Studies vary in their patient populations, inclusion and exclusion criteria, threshold levels and/or combination of thresholds (e.g. pre-contrast $\mathrm{CT}+$ delayed contrast wash-out thresholds). There are also a variety of methods by which the malignant or benign status of the lesions has been determined, and many of the studies are too small to have any identified adrenocortical carcinomas $(76,77)$, and hence the ability of the given thresholds to identify these lesions is unknown.

With these caveats in mind, the most studied imaging modality for diagnosis of adrenal adenomas is CT, with or without delayed contrast washout. The typical performance of CT is sensitivity of $64 \%$ (78), $66.7 \%$ in lesions over $2 \mathrm{~cm}$ (79), 71\% (75), 72\% (76), 92\% using 10 min contrast washout (80), 96\% (81) and 96\% using $3 \mathrm{~min}$ contrast washout (82). Using combined parameters, CT performance for identifying adenomas can range from $42 \%$ (using non-contrast CT HU $\leq 20$ plus size $\leq 4 \mathrm{~cm} \mathrm{(83))} \mathrm{to} 100 \%$ (when lesions with precontrast $\mathrm{HU}<0$ are excluded (considered benign) and those with pre-contrast $\mathrm{HU}>43$ are excluded (considered suspicious of malignancy) and when cysts, myelolipomas and phaeochromocytomas are excluded, and using an absolute percentage contrast washout threshold at $10 \mathrm{~min}$ of $52 \%(77)$ ). Collating the data from these varied studies gives an approximate sensitivity of $75 \%$ (mean sensitivity $78 \%$ and median sensitivity $72 \%$ ). This $75 \%$ figure is consistent with other estimates $(75 \%(79)$ and $68-89 \%(4))$.

Typical specificity of CT for diagnosing adrenal adenomas is $85.7 \%$ (79) in lesions over $2 \mathrm{~cm}, 92 \%$ using delayed enhanced CT (82), 95\% (78), 95\% (76), 95\% using delayed enhanced CT (80), 96\% using delayed CT (81), 100\% (75), 98\% using various exclusions as detailed above (77) and $100 \%$ using non-contrast CT $\mathrm{HU} \leq 20$ plus size $\leq 4 \mathrm{~cm}$ (83). Collating the data from these varied studies gives an approximate specificity of $95 \%$ (mean and median specificity of $95 \%$ ). This $95 \%$ figure is consistent with other estimates (93-100\% (4)).

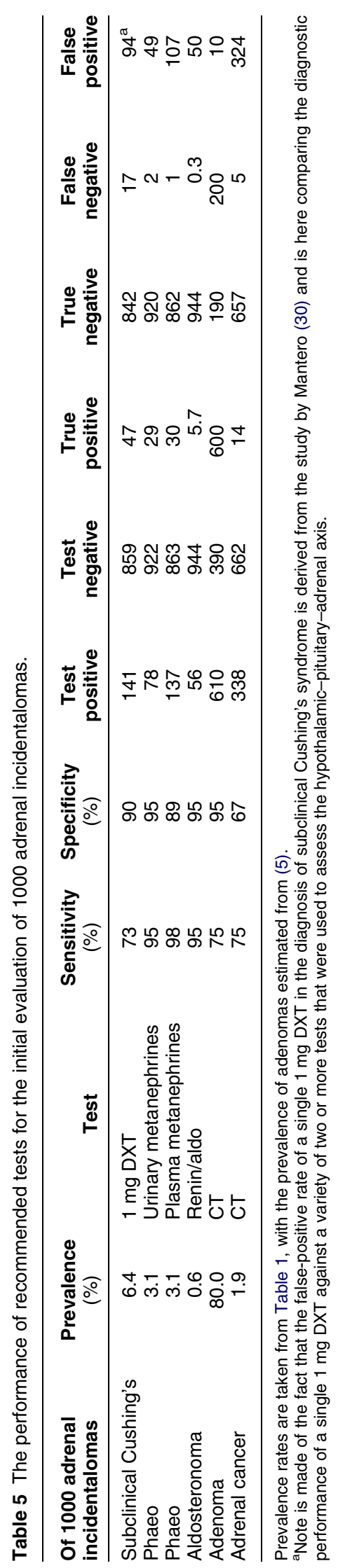


Studies addressing the detection of adrenocortical carcinoma, which have found a $4 \mathrm{~cm}$ cut-off, had $90 \%$ sensitivity, even though $76 \%$ of lesions greater than $4 \mathrm{~cm}$ were benign $(27,84)$. Another study found that in tumours $>3 \mathrm{~cm}$, CT had a sensitivity of $75 \%$ and specificity of $67 \%$ for detecting adrenocortical carcinoma (85). Hence, the ability of CT to correctly diagnose this low-prevalence pathology is considerably lower compared to the ability of CT to differentiate between adenomatous and other non-adenomatous lesions.

The performance of the recommended investigations for the initial evaluation and during the follow-up of adrenal incidentalomas initially thought to be benign and non-functional is given in Tables 5 and 6 .

\section{Risk of cancer due to imaging-associated radiation exposure}

The most commonly used imaging modality in assessing adrenal incidentaloma is CT. X-ray imaging techniques, including $\mathrm{CT}$, involve ionising radiation, which carries an associated risk of inducing malignancy. The magnitude of that risk has been estimated from studies where populations have been exposed to a known dose of ionising radiation, and the subsequent increase in cancer-associated deaths has been ascertained. This has been studied in depth by the United Nations Scientific Committee on the Effects of Atomic Radiation who publish regular reports, updated by the latest mortality data. The latest report assessing lifetime mortality risk for total cancer associated with ionising radiation was published in 2006 (86), and includes data from a cohort of 86611 survivors of atomic bombings in Japan. Although some of this cohort received large doses of radiation (up to $4000 \mathrm{mSv}$ ), the cohort is fundamentally a moderate dose cohort, with the mean dose in the exposed group being $200 \mathrm{mSv}$, with $>50 \%$ of the exposed individuals in the cohort having doses $<50 \mathrm{mSv}(86,87)$. Other studies have looked at fractionated or chronic low-dose exposure, including the IARC 15-country nuclear worker study (88), the Techa River contamination with liquid radioactive waste $(89,90)$ and the Semipalatinsk study of the effects of local fallout from Soviet atmospheric nuclear weapons testing in Kazakhstan (91). There are concerns about bias in these four studies, which found substantially elevated risks for solid cancers compared with the Japanese atomic bomb cohort. These studies have low statistical precision, with wide confidence intervals for the risk estimates, which at least in the Techa River and nuclear worker study overlapped those from the Japanese cohort (86).

The effective dose of radiation associated with an abdominal CT scan is typically $10 \mathrm{mSv}$ (92) (http:// www.icrp.org/docs/Rad_for_GP_for_web.pdf; http:// www.fda.gov/cdrh/ct/risks. $30 \mathrm{mSv}(94)$ ), which is equivalent to 3.3 years of

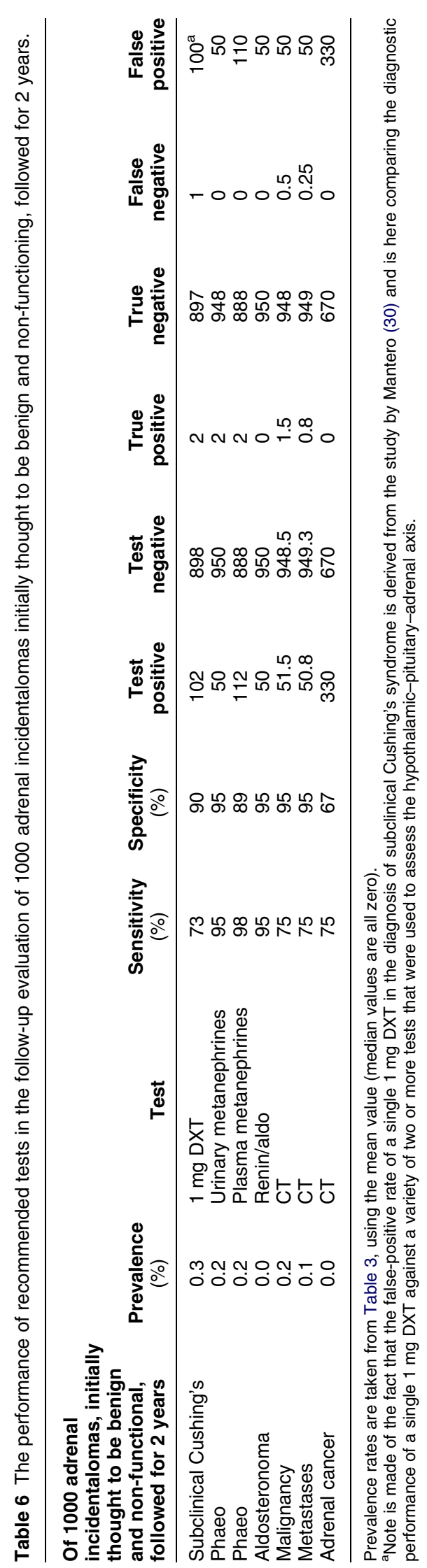

www.eje-online.org 
natural background radiation exposure. The effective dose of $10 \mathrm{mSv}$ for $\mathrm{CT}$ abdomen compares to $2 \mathrm{mSv}$ for CT head, $7 \mathrm{mSv}$ for barium enema, $1.3 \mathrm{mSv}$ for lumbar spine plain X-ray and $0.02 \mathrm{mSv}$ for chest X-ray. Targeted CT of the adrenals may involve a lower radiation dose, with a scan of the upper abdomen delivering $\sim 5 \mathrm{mSv}$ (95). However, adrenal protocols involving delayed contrast washout measurement require scanning the adrenal region twice, and hence the total effective dose may be similar to a whole abdomen scan, but is delivered to the upper abdominal organs, which would consequently receive a higher dose than during a whole abdominal scan.

There is direct epidemiological evidence from human populations demonstrating that acute exposure to ionising radiation at doses in the $10-50 \mathrm{mSv}$ range (i.e. the organ dose range typically delivered by two or three CT scans) increases the risk of some cancers (87). The corresponding CT-related risks can thus be directly assessed without the need to extrapolate measured risks to lower doses (92). Risk estimates for radiation-induced mortality for solid cancers and leukaemia, with a test dose of $10 \mathrm{mSv}$, are $\sim 4.8 \%$ per Sv. For a CT scan of the abdomen, the estimated associated lifetime absolute risk of cancer-related death as a direct consequence of the radiation dose received during the scan $(10 \mathrm{mSv})$ is $0.048 \%$ (86). An abdominal CT scan is therefore estimated to cause one cancer-related death for every 1000 (http://www.nap.edu/catalog/11340.html) 2000 (http://www.icrp.org/docs/Rad_for_GP_for_web. pdf) abdominal CT scans. More recent estimates based on the lifetime risk of fatal cancer as a result of a single abdominal CT scan in those aged over 30 years (as in the vast majority of adrenal incidentaloma patients) are lower, in the region of one death per 5000 scans (92). The precise magnitude of the fatal cancer risk associated with CT scanning remains a matter of some debate, but it is generally accepted that although the risk is relatively small, it is not zero, and hence should be considered before ordering CT imaging, especially where the expected diagnostic yield is low.

\section{Economic cost}

In our institution, the cost of blood tests to assess functionality (routine biochemistry, cortisol as part of $1 \mathrm{mg}$ DXT, urinary catecholamines and metanephrines, renin and aldosterone) is $\sim$ NZ\$ 175 (US\$ 120). Additional tests such as 24-h UFC, ACTH, DHEAS, 17-OHP and serum catecholamines and metanephrines add an additional NZ\$290 (US\$ 200). An abdominal CT with contrast costs NZ\$ 720 (US\$ 500). Therefore, for baseline assessment, investigations cost between NZ\$ 895 (US\$ 620) and NZ\$ 1185 (US\$ 820), depending on how many blood and urine tests are ordered.

\section{Implications of current clinical recommendations}

There are a number of consensus or clinical guidance publications with arguably the more influential publications being those by Young (2), the UpToDate review of which Young is the first author (3), and the NIH consensus statement (1). The recommendations are summarised in Table 7 . The routine application of the recommended strategy for follow-up of adrenal incidentalomas is likely to be costly in terms of financial expense, radiation exposure and risk of inducing fatal cancer. Furthermore, this approach carries a high risk of false-positive diagnoses and the associated emotional burden to each patient, while

Table 7 Summary of current clinical recommendations (1-3).

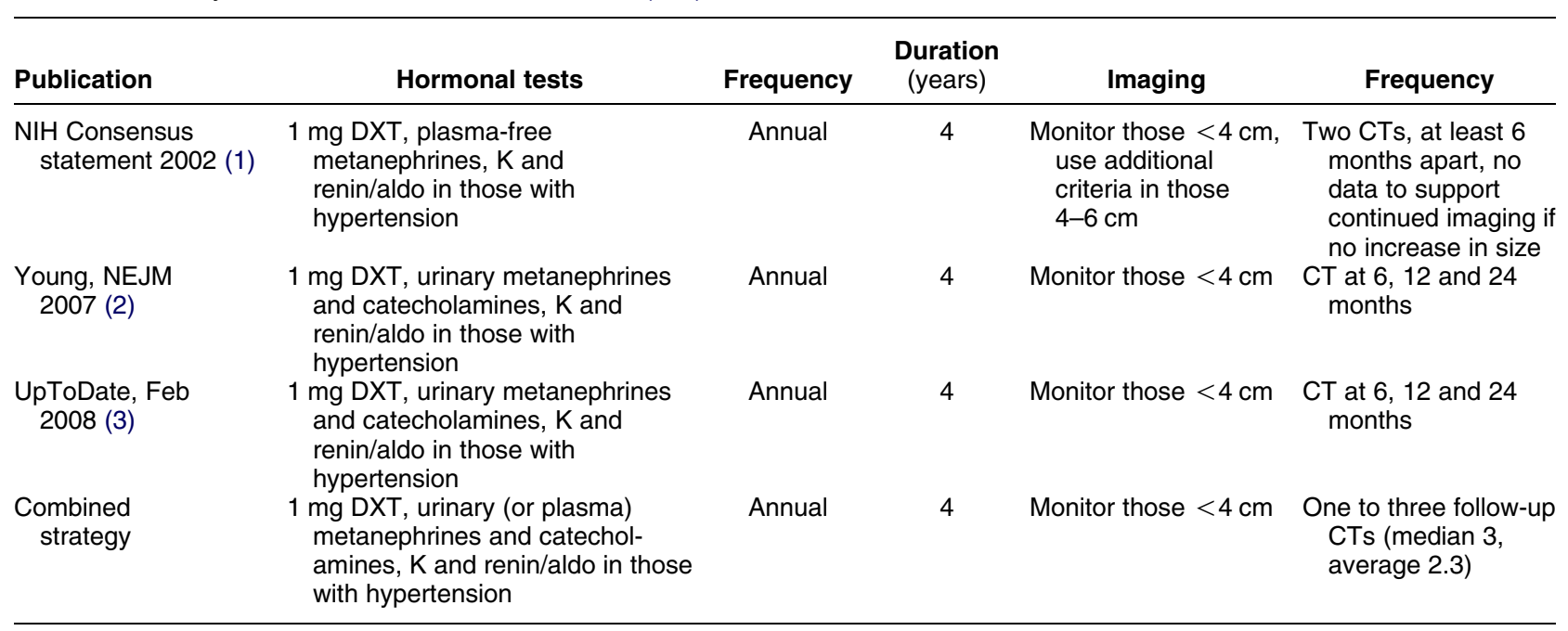


Table 8 Implications of current clinical recommendations, applying the data described in the current paper.

Approximate risk of event during 2-year radiological follow-up and 4-year biochemical follow-up of an adrenal incidentaloma initially thought to be benign and non-functional

Approximate financial cost of tests

Radiation exposure from CT imaging during follow-up

Risk of inducing fatal cancer from radiation exposure during follow-up CT imaging

Risk of detecting cancer during follow-up

Risk of detecting non-metastatic cancer during follow-up

Risk of false-positive diagnosis/suspicion of malignancy during CT imaging

Risk of false-positive diagnosis of subclinical Cushing's syndrome

Risk of true-positive diagnosis of subclinical Cushing's syndrome

1630 US\$ (based on average 2.3 scans)

$23 \mathrm{mSv}$

1 in 430 to 1 in $2170^{a}$

$0-1$ in $500^{\mathrm{b}}$

$0-1$ in 1000

1 in $20^{\circ}$

Between 1 in 10 and 1 in $4^{d}$

1 in $250^{\mathrm{e}}$

${ }^{\mathrm{a} B a s e d}$ on risk of causing fatal cancer of between 1 in 1000 and 1 in $5000 \mathrm{CT}$ scans, and $2.3 \mathrm{CT}$ scans occurring during follow-up.

${ }^{\mathrm{b}}$ Approximately, half of tumours detected will be metastases, and so diagnosis unlikely to affect outcome.

${ }^{\mathrm{c}}$ Based on specificity of CT of $95 \%$ for malignancy, see Table 6.

${ }^{\mathrm{d} B a s e d}$ on specificity of $1 \mathrm{mg}$ DXT of $90 \%$ and four annual follow-up tests.

${ }^{\text {e}}$ Based on 2 cases per 1000 developing over 2 years of follow-up, see Table 6.

only offering a small chance of a true-positive diagnosis (often of debatable clinical benefit, such as subclinical Cushing's syndrome or an adrenal metastasis). At initial evaluation, the false-positive rate for functional or malignant lesions is typically 5 times greater than the true-positive rate, and during followup of adrenal incidentalomas initially considered to be benign and non-functional, the false-positive rate is typically 50 times greater than the true-positive rate (Tables 5 and 6).

The cost to the patient of repeated clinic visits both financially, and also in terms of inconvenience and psychological distress, is impossible to quantify but is likely to be significant. The financial costs to the healthcare system are approximately US\$ 1630 for the tests alone (based on performing 2.3 CT scans, plus annual routine biochemistry, cortisol as part of $1 \mathrm{mg}$ DXT, urinary catecholamines and metanephrines, renin and aldosterone for 4 years), without allowing for additional costs such as hospital overheads, consultation time and further evaluation of positive results. There should also be consideration of the costs associated with unnecessary adrenalectomy.

The CT imaging recommended exposes the average patient to $23 \mathrm{mSv}$ of ionising radiation, and so exposes the individual to a chance of inducing fatal cancer of between 1 in 430 and 1 in 2170 (based on a risk of death of between 1 in 1000 and 1 in 5000, per single abdominal CT scan of $10 \mathrm{mSv}$ ). This is comparable with the risk of detecting an adrenal malignancy during 3 year follow-up of between 0 and 1 in 500 (based on median incidence of $0 \%$, mean incidence $0.2 \%$; Table 3 ).

It is important to comment in more detail on the two cancers detected during follow-up in the papers included in this review. The first was a renal carcinoma metastasis in a patient with a known history of renal carcinoma (19), and since patients with known malignancy are at increased risk of developing adrenal metastases, one could reasonably argue that this study should have been excluded from this analysis. Moreover, there is no proven benefit of adrenalectomy in patients found to have adrenal metastases during the investigation of adrenal incidentalomas (1). The other malignancy detected during follow-up showed a mass enlargement after 6 months and the patient was eventually diagnosed with non-Hodgkin's lymphoma (45).

Current practice of interval CT imaging, consisting of two to three follow-up scans, is therefore almost as likely to cause fatal cancer as it is to find cancer (half of which are likely to already be disseminated), and so on a policy level is difficult to justify. In addition, because of the low prevalence of malignancy or endocrine functionality developing during follow-up of an adrenal incidentaloma initially thought to be benign and non-functional, the performance of the available diagnostic tests is poor, with many more false positives than true positives (Table 8).

\section{Conclusion}

The precise figures presented are clearly open to criticism, partly due to the heterogeneity of the studies that have, and have not, been included in this review. However, such debate would distract from the broad conclusions that can reasonably be drawn from the data in the literature, which can be summarised as follows:

- The prevalence of endocrine functionality in adrenal incidentalomas is low $(<10 \%)$.

- The prevalence of malignancy in adrenal incidentalomas is lower $(<5 \%)$.

- The majority of cases of endocrine functionality are due to subclinical Cushing's syndrome, the clinical importance of which is debatable.

- The risk of an adrenal incidentaloma, initially thought to be benign and non-functional, subsequently developing clinically important endocrine functionality or malignancy over 2-4 years is low, in the region of $<1 \%$, but does vary depending upon the definition of, and extent of testing for, subclinical Cushing's syndrome. 
- Due to the low prevalence of these conditions, especially during follow-up, and the less-than-ideal performance of the tests used to diagnose endocrine functionality and malignancy, the chances of falsepositive tests are many times higher than the chance of a true-positive result.

- The chance of detecting malignancy during CT follow-up of adrenal incidentalomas initially thought to be benign and non-functional is broadly similar to the chance of inducing fatal cancer from the ionising radiation delivered by these $\mathrm{CT}$ scans.

In the light of these data, current practice is arguably difficult to defend on a number of levels including the standards of Hippocrates 'Primum non nocere' (first do no harm). Acceptable results, but with considerably less expense, both financial and emotional due to falsepositive test results, could be obtained by taking reasonable steps to exclude functionality and malignancy at presentation (such as those recommended by the NIH Consensus statement and leading reviews summarised in Table 7 (1-3)), but not embarking on either biochemical or imaging follow-up in those thought to be benign and non-functioning. For those in a 'grey zone' - for example 4-6 cm lesions or other suspicious imaging characteristics, a single imaging follow-up study 3-6 months later could be undertaken. This follow-up imaging could be with MRI to reduce radiation exposure, although keeping with the same imaging modality has technical advantages for interval comparison. Based on the data presented, the default position after initial evaluation should be to either excise the lesion or discharge from follow-up. The small number of patients who subsequently develop clinical signs of hormone excess or malignancy should be investigated appropriately.

Further follow-up studies of patients with adrenal incidentalomas are required to define the optimal investigation algorithm that balances the false-positive and negative rates of endocrine test protocols as well as the financial and emotional costs of investigation. We would also argue that the data linking radiation exposure with future cancer risk must also be considered when formulating a management algorithm. Based on the available data reviewed in this paper, our view is that current clinical recommendations for the assessment and management of adrenal incidentalomas have yet to find the optimal balance.

\section{Declaration of interest}

The authors declare that there is no conflict of interest that could be perceived as prejudicing the impartiality of the research reported.

\section{Funding}

This research did not receive any specific grant from any funding agency in the public, commercial or not-for-profit sector.

\section{References}

1 NIH. State-of-the-science statement on management of the clinically inapparent adrenal mass ('incidentaloma'). NIH Consensus and State-of-the-Science Statements 200219 1-25.

2 Young WF Jr. Clinical practice. The incidentally discovered adrenal mass. New England Journal of Medicine 2007356 601-610.

3 Young WF Jr \& Kaplan NM Eds. The Adrenal Incidentaloma. UpToDate Inc., accessed 08/04/2008, 2008.

4 Mansmann G, Lau J, Balk E, Rothberg M, Miyachi Y \& Bornstein SR. The clinically inapparent adrenal mass: update in diagnosis and management. Endocrine Reviews 200425 309-340.

5 Barzon L, Sonino N, Fallo F, Palu G \& Boscaro M. Prevalence and natural history of adrenal incidentalomas. European Journal of Endocrinology 2003149 273-285.

6 Tutuncu NB \& Gedik O. Adrenal incidentaloma: report of 33 cases. Journal of Surgical Oncology 199970 247-250.

7 Luton JP, Martinez M, Coste J \& Bertherat J. Outcome in patients with adrenal incidentaloma selected for surgery: an analysis of 88 cases investigated in a single clinical center. European Journal of Endocrinology 2000143 111-117.

8 Aydintug S, Kocak S \& Eraslan S. Primary non-functioning tumours of the adrenal cortex: an eight-year experience in Turkey. European Journal of Surgery $1996 \mathbf{1 6 2} 275-278$.

9 Lee JA, Zarnegar R, Shen WT, Kebebew E, Clark OH \& Duh OY. Adrenal incidentaloma, borderline elevations of urine or plasma metanephrine levels, and the 'subclinical' pheochromocytoma. Archives of Surgery 2007142 870-873 (discussion 873-874).

10 Aso Y \& Homma Y. A survey on incidental adrenal tumors in Japan. Journal of Urology 1992147 1478-1481.

11 Murai M, Baba S, Nakashima J \& Tachibana M. Management of incidentally discovered adrenal masses. World Journal of Urology $1999179-14$.

12 Proye C, Jafari Manjili M, Combemale F, Pattou F, Ernst O, Carnaille B \& Wemeau JL. Experience gained from operation of 103 adrenal incidentalomas. Langenbeck's Archives of Surgery 1998 383 330-333.

13 Grumbach MM, Biller BM, Braunstein GD, Campbell KK, Carney JA, Godley PA, Harris EL, Lee JK, Oertel YC, Posner MC, Schlechte JA \& Wieand HS. Management of the clinically inapparent adrenal mass ('incidentaloma'). Annals of Internal Medicine 2003138 424-429.

14 Fontana D, Porpiglia F, Destefanis P, Fiori C, Ali A, Terzolo M, Osella G \& Angeli A. What is the role of ultrasonography in the follow-up of adrenal incidentalomas? The Gruppo Piemontese Incidentalomi Surrenalici Urology 199954 612-616.

15 Ambrosi B, Peverelli S, Passini E, Re T, Ferrario R, Colombo P, Sartorio A \& Faglia G. Abnormalities of endocrine function in patients with clinically 'silent' adrenal masses. European Journal of Endocrinology 1995132 422-428.

16 Bulow B \& Ahren B. Adrenal incidentaloma-experience of a standardized diagnostic programme in the Swedish prospective study. Journal of Internal Medicine 2002252 239-246.

17 Boland GW, Goldberg MA, Lee MJ, Mayo-Smith WW, Dixon J, McNicholas MM \& Mueller PR. Indeterminate adrenal mass in patients with cancer: evaluation at PET with 2-[F-18]-fluoro-2deoxy-D-glucose. Radiology 1995194 131-134.

18 Burt M, Heelan RT, Coit D, McCormack PM, Bains MS, Martini N, Rusch V \& Ginsberg RJ. Prospective evaluation of unilateral adrenal masses in patients with operable non-small-cell lung cancer. Impact of magnetic resonance imaging. Journal of Thoracic and Cardiovascular Surgery 1994107 584-588 (discussion 588-589).

19 Tsvetov G, Shimon I \& Benbassat C. Adrenal incidentaloma: clinical characteristics and comparison between patients with and without extraadrenal malignancy. Journal of Endocrinological Investigation 200730 647-652.

20 Kobayashi S, Seki T, Nonomura K, Gotoh T, Togashi M \& Koyanagi T. Clinical experience of incidentally discovered adrenal tumor with particular reference to cortical function. Journal of Urology 1993150 8-12. 
21 Xiao XR, Ye LY, Shi LX, Cheng GF, Li YT \& Zhou BM. Diagnosis and treatment of adrenal tumours: a review of 35 years experience. British Journal of Urology 199882 199-205.

22 Kasperlik-Zeluska AA, Roslonowska E, Slowinska-Srzednicka J. Migdalska B, Jeske W, Makowska A \& Snochowska H. Incidentally discovered adrenal mass (incidentaloma): investigation and management of 208 patients. Clinical Endocrinology 199746 29-37.

23 Favia G, Lumachi F, Basso S \& D'Amico DF. Management of incidentally discovered adrenal masses and risk of malignancy. Surgery 2000128 918-924.

24 Nakajo M, Nakabeppu Y, Yonekura R, Iwashita S \& Goto T. The role of adrenocortical scintigraphy in the evaluation of unilateral incidentally discovered adrenal and juxtaadrenal masses. Annals of Nuclear Medicine 19937 157-166.

25 Virkkala A, Valimaki M, Pelkonen R, Huikuri K, Kahri A, Kivisaari L, Korhonen T, Salmi J \& Seppala P. Endocrine abnormalities in patients with adrenal tumours incidentally discovered on computed tomography. Acta Endocrinologica 1989 $12167-72$.

26 Terzolo M, Ali A, Osella G \& Mazza E. Prevalence of adrenal carcinoma among incidentally discovered adrenal masses. A retrospective study from 1989 to 1994. Gruppo Piemontese Incidentalomi Surrenalici. Archives of Surgery 1997132 914-919.

27 Angeli A, Osella G, Ali A \& Terzolo M. Adrenal incidentaloma: an overview of clinical and epidemiological data from the National Italian Study Group. Hormone Research 199747 279-283.

28 Barzon L, Scaroni C, Sonino N, Fallo F, Gregianin M, Macri C \& Boscaro M. Incidentally discovered adrenal tumors: endocrine and scintigraphic correlates. Journal of Clinical Endocrinology and Metabolism $1998 \mathbf{8 3} 55-62$.

29 Osella G, Terzolo M, Borretta G, Magro G, Ali A, Piovesan A, Paccotti P \& Angeli A. Endocrine evaluation of incidentally discovered adrenal masses (incidentalomas). Journal of Clinical Endocrinology and Metabolism 199479 1532-1539.

30 Mantero F, Terzolo M, Arnaldi G, Osella G, Masini AM, Ali A, Giovagnetti M, Opocher G \& Angeli A. A survey on adrenal incidentaloma in Italy. Study Group on Adrenal Tumors of the Italian Society of Endocrinology. Journal of Clinical Endocrinology and Metabolism 200085 637-644.

31 Terzolo M, Osella G, Ali A, Reimondo G, Borretta G, Magro GP, Luceri S, Paccotti P \& Angeli A. Adrenal incidentaloma, a five year experience. Minerva Endocrinologica 199520 69-78.

32 Flecchia D, Mazza E, Carlini M, Blatto A, Olivieri F, Serra G, Camanni F \& Messina M. Reduced serum levels of dehydroepiandrosterone sulphate in adrenal incidentalomas: a marker of adrenocortical tumour. Clinical Endocrinology 1995 42 129-134.

33 Barry MK, van Heerden JA, Farley DR, Grant CS, Thompson GB \& Ilstrup DM. Can adrenal incidentalomas be safely observed? World Journal of Surgery 199822 599-603 (discussion 603-604).

34 Herrera MF, Grant CS, van Heerden JA, Sheedy PF \& Ilstrup DM. Incidentally discovered adrenal tumors: an institutional perspective. Surgery $19911101014-1021$.

35 Song JH, Chaudhry FS \& Mayo-Smith WW. The incidental indeterminate adrenal mass on $\mathrm{CT}(>10 \mathrm{H})$ in patients without cancer: is further imaging necessary? Follow-up of 321 consecutive indeterminate adrenal masses American Journal of Roentgenology 2007189 1119-1123.

36 Rossi R, Tauchmanova L, Luciano A, Di Martino M, Battista C, Del Viscovo L, Nuzzo V \& Lombardi G. Subclinical Cushing's syndrome in patients with adrenal incidentaloma: clinical and biochemical features. Journal of Clinical Endocrinology and Metabolism 200085 1440-1448.

37 Bondanelli M, Campo M, Trasforini G, Ambrosio MR, Zatelli MC, Franceschetti P, Valentini A, Pansini R \& degli Uberti EC. Evaluation of hormonal function in a series of incidentally discovered adrenal masses. Metabolism 199746 107-113.

38 Seppel T \& Schlaghecke R. Subclinical hypercortisolism in incidentally detected adrenal adenoma. Deutsche Medizinische Wochenschrift 1996121 503-507 (discussion 508).
39 Emral R, Uysal AR, Asik M, Gullu S, Corapcioglu D, Tonyukuk V \& Erdogan G. Prevalence of subclinical Cushing's syndrome in 70 patients with adrenal incidentaloma: clinical, biochemical and surgical outcomes. Endocrine Journal 200350 399-408.

40 Reincke M, Nieke J, Krestin GP, Saeger W, Allolio B \& Winkelmann W. Preclinical Cushing's syndrome in adrenal 'incidentalomas': comparison with adrenal Cushing's syndrome. Journal of Clinical Endocrinology and Metabolism $1992 \mathbf{7 5}$ 826-832.

41 Bastounis EA, Karayiannakis AJ, Anapliotou ML, Nakopoulou L, Makri GG \& Papalambros EL. Incidentalomas of the adrenal gland: diagnostic and therapeutic implications. American Surgeon 1997 63 356-360.

42 Bardet S, Rohmer V, Murat A, Guillemot C, Marechaud R, Chupin M, Lecomte P, Simon D, Delemer B, Schneebelli S, Beutter D, Jacquin V, Peltier P \& Charbonnel B. ${ }^{131} \mathrm{I}-6$ betaiodomethylnorcholesterol scintigraphy: an assessment of its role in the investigation of adrenocortical incidentalomas. Clinical Endocrinology 199644 587-596.

43 Barzon L, Scaroni C, Sonino N, Fallo F, Paoletta A \& Boscaro M. Risk factors and long-term follow-up of adrenal incidentalomas. Journal of Clinical Endocrinology and Metabolism $1999 \mathbf{8 4}$ 520-526.

44 Bulow B, Jansson S, Juhlin C, Steen L, Thoren M, Wahrenberg H, Valdemarsson S, Wangberg B \& Ahren B. Adrenal incidentaloma follow-up results from a Swedish prospective study. European Journal of Endocrinology 2006154 419-423.

45 Libe R, Dall'Asta C, Barbetta L, Baccarelli A, Beck-Peccoz P \& Ambrosi B. Long-term follow-up study of patients with adrenal incidentalomas. European Journal of Endocrinology $2002 \mathbf{1 4 7}$ 489-494.

46 Siren J, Tervahartiala P, Sivula A \& Haapiainen R. Natural course of adrenal incidentalomas: seven-year follow-up study. World Journal of Surgery 200024 579-582.

47 Grossrubatscher E, Vignati F, Possa M \& Lohi P. The natural history of incidentally discovered adrenocortical adenomas: a retrospective evaluation. Journal of Endocrinological Investigation 2001 24 846-855.

48 Bencsik Z, Szabolcs I, Goth M, Voros A, Kaszas I, Gonczi J, Kovacs L, Dohan O \& Szilagyi G. Incidentally detected adrenal tumours (incidentalomas): histological heterogeneity and differentiated therapeutic approach. Journal of Internal Medicine 1995 237 585-589.

49 Mantero F \& Arnaldi G. Management approaches to adrenal incidentalomas. A view from Ancona, Italy. Endocrinology and Metabolism Clinics of North America 200029 107-125 (ix).

50 Sippel RS \& Chen H. Subclinical Cushing's syndrome in adrenal incidentalomas. Surgical Clinics of North America $2004 \mathbf{8 4}$ $875-885$.

51 Nieman LK, Biller BM, Findling JW, Newell-Price J, Savage MO, Stewart PM \& Montori VM. The diagnosis of Cushing's syndrome: an Endocrine Society Clinical Practice Guideline. Journal of Clinical Endocrinology and Metabolism 200893 1526-1540.

52 Morioka M, Fujii T, Matsuki T, Jo Y, Kobayashi T, Tanaka H, Ohashi T \& Kondo K. Preclinical Cushing's syndrome: report of seven cases and a review of the literature. International Journal of Urology 20007 126-132.

53 Bernini G, Moretti A, Iacconi P, Miccoli P, Nami R, Lucani B \& Salvetti A. Anthropometric, haemodynamic, humoral and hormonal evaluation in patients with incidental adrenocortical adenomas before and after surgery. European Journal of Endocrinology 2003148 213-219.

54 Tsagarakis S, Kokkoris P, Roboti C, Malagari C, Kaskarelis J, Vlassopoulou V, Alevizaki C \& Thalassinos N. The low-dose dexamethasone suppression test in patients with adrenal incidentalomas: comparisons with clinically euadrenal subjects and patients with Cushing's syndrome. Clinical Endocrinology 199848 627-633.

55 Pacak K, Eisenhofer G, Ahlman H, Bornstein SR, GimenezRoqueplo AP, Grossman AB, Kimura N, Mannelli M, McNicol AM \& Tischler AS. Pheochromocytoma: recommendations for clinical 
practice from the First International Symposium. October 2005. Nature Clinical Practice. Endocrinology \& Metabolism 20073 92-102.

56 Lenders JW, Pacak K, Walther MM, Linehan WM, Mannelli M, Friberg P, Keiser HR, Goldstein DS \& Eisenhofer G. Biochemical diagnosis of pheochromocytoma: which test is best? Journal of the American Medical Association 2002287 1427-1434.

57 Perry CG, Sawka AM, Singh R, Thabane L, Bajnarek J \& Young WF Jr. The diagnostic efficacy of urinary fractionated metanephrines measured by tandem mass spectrometry in detection of pheochromocytoma. Clinical Endocrinology 2007 66 703-708.

58 Sawka AM, Jaeschke R, Singh RJ \& Young WF Jr. A comparison of biochemical tests for pheochromocytoma: measurement of fractionated plasma metanephrines compared with the combination of 24-hour urinary metanephrines and catecholamines. Journal of Clinical Endocrinology and Metabolism 200388 553-558.

59 Boyle JG, Davidson DF, Perry CG \& Connell JM. Comparison of diagnostic accuracy of urinary free metanephrines, vanillyl mandelic acid, and catecholamines and plasma catecholamines for diagnosis of pheochromocytoma. Journal of Clinical Endocrinology and Metabolism 200792 4602-4608.

60 Brain KL, Kay J \& Shine B. Measurement of urinary metanephrines to screen for pheochromocytoma in an unselected hospital referral population. Clinical Chemistry 200652 2060-2064.

61 Hernandez FC, Sanchez M, Alvarez A, Diaz J, Pascual R, Perez M, Tovar I \& Martinez P. A five-year report on experience in the detection of pheochromocytoma. Clinical Biochemistry 200033 649-655.

62 Heron E, Chatellier G, Billaud E, Foos E \& Plouin PF. The urinary metanephrine-to-creatinine ratio for the diagnosis of pheochromocytoma. Annals of Internal Medicine $1996125300-303$.

63 Eisenhofer G, Siegert G, Kotzerke J, Bornstein SR \& Pacak K. Current progress and future challenges in the biochemical diagnosis and treatment of pheochromocytomas and paragangliomas. Hormone and Metabolic Research 200840 329-337.

64 Vaclavik J, Stejskal D, Lacnak B, Lazarova M, Jedelsky L, Kadalova L, Janosova M, Frysak Z \& Vlcek P. Free plasma metanephrines as a screening test for pheochromocytoma in lowrisk patients. Journal of Hypertension 200725 1427-1431.

65 Unger N, Pitt C, Schmidt IL, Walz MK, Schmid KW, Philipp T, Mann K \& Petersenn S. Diagnostic value of various biochemical parameters for the diagnosis of pheochromocytoma in patients with adrenal mass. European Journal of Endocrinology $2006 \mathbf{1 5 4}$ 409-417.

66 Nishizaka MK, Pratt-Ubunama M, Zaman MA, Cofield S \& Calhoun DA. Validity of plasma aldosterone-to-renin activity ratio in African American and white subjects with resistant hypertension. American Journal of Hypertension 200518 805-812.

67 Trenkel S, Seifarth C, Schobel H, Hahn EG \& Hensen J. Ratio of serum aldosterone to plasma renin concentration in essential hypertension and primary aldosteronism. Experimental and Clinical Endocrinology and Diabetes $200211080-85$.

68 Eng PH, Tan KE, Khoo DH, Tan CE, Lim HS, Lim SC, Koh LK, Ho SC, Tai ES \& Fok AC. Aldosterone to renin ratios in the evaluation of primary aldosteronism. Annals of the Academy of Medicine of Singapore 199726 762-766.

69 Weinberger $\mathrm{MH} \&$ Fineberg NS. The diagnosis of primary aldosteronism and separation of two major subtypes. Archives of Internal Medicine 1993153 2125-2129.

70 Bernini G, Moretti A, Orlandini C, Berti P, Miccoli P, Bardini M, Taurino C, Bernini M \& Salvetti A. Plasma and urine aldosterone to plasma renin activity ratio in the diagnosis of primary aldosteronism. Journal of Hypertension 2008 26 981-988.

71 Giacchetti G, Ronconi V, Lucarelli G, Boscaro M \& Mantero F. Analysis of screening and confirmatory tests in the diagnosis of primary aldosteronism: need for a standardized protocol. Journal of Hypertension 200624 737-745.

72 Vierhapper H. Determination of the aldosterone/renin ratio in 269 patients with adrenal incidentaloma. Experimental and Clinical Endocrinology and Diabetes 2007115 518-521.
73 Tzanela M, Effremidis G, Vassiliadi D, Szabo A, Gavalas N, Valatsou A, Botoula E \& Thalassinos NC. The aldosterone to renin ratio in the evaluation of patients with incidentally detected adrenal masses. Endocrine 200732 136-142.

74 Unger N, Lopez Schmidt I, Pitt C, Walz MK, Philipp T, Mann K \& Petersenn S. Comparison of active renin concentration and plasma renin activity for the diagnosis of primary hyperaldosteronism in patients with an adrenal mass. European Journal of Endocrinology $2004150517-523$.

75 Hennings J, Hellman P, Ahlstrom H \& Sundin A. Computed tomography, magnetic resonance imaging and (11)C-metomidate positron emission tomography for evaluation of adrenal incidentalomas. European Journal of Radiology 20092 314-323.

76 Park SH, Kim MJ, Kim JH, Lim JS \& Kim KW. Differentiation of adrenal adenoma and nonadenoma in unenhanced CT: new optimal threshold value and the usefulness of size criteria for differentiation. Korean Journal of Radiology 20078 328-335.

77 Blake MA, Kalra MK, Sweeney AT, Lucey BC, Maher MM, Sahani DV, Halpern EF, Mueller PR, Hahn PF \& Boland GW. Distinguishing benign from malignant adrenal masses: multidetector row CT protocol with 10-minute delay. Radiology 2006 238 578-585.

78 Miyake H, Takaki H, Matsumoto S, Yoshida S, Maeda T \& Mori H. Adrenal nonhyperfunctioning adenoma and nonadenoma: CT attenuation value as discriminative index. Abdominal Imaging 199520 559-562.

79 Lumachi F, Borsato S, Tregnaghi A, Basso SM, Marchesi P, Ciarleglio F, Fassina A \& Favia G. CT-scan, MRI image-guided FNA cytology of incidental adrenal masses. European Journal of Surgical Oncology 200329 689-692.

80 Szolar DH \& Kammerhuber FH. Adrenal adenomas and nonadenomas: assessment of washout at delayed contrastenhanced CT. Radiology 1998207 369-375.

81 Boland GW, Hahn PF, Pena C \& Mueller PR. Adrenal masses: characterization with delayed contrast-enhanced CT. Radiology $1997202693-696$.

82 Szolar DH \& Kammerhuber F. Quantitative CT evaluation of adrenal gland masses: a step forward in the differentiation between adenomas and nonadenomas? Radiology $1997 \mathbf{2 0 2}$ 517-521.

83 Hamrahian AH, Ioachimescu AG, Remer EM, Motta-Ramirez G, Bogabathina H, Levin HS, Reddy S, Gill IS, Siperstein A \& Bravo EL. Clinical utility of noncontrast computed tomography attenuation value (Hounsfield Units) to differentiate adrenal adenomas/hyperplasias from nonadenomas: Cleveland clinic experience. Journal of Clinical Endocrinology and Metabolism 200590 871-877.

84 Young WF Jr. Management approaches to adrenal incidentalomas. A view from Rochester, Minnesota. Endocrinology and Metabolism Clinics of North America 200029 159-185 (x).

85 Lumachi F, Borsato S, Tregnaghi A, Marino F, Fassina A, Zucchetta P, Marzola MC, Cecchin D, Bui F, Iacobone M \& Favia G. High risk of malignancy in patients with incidentally discovered adrenal masses: accuracy of adrenal imaging and image-guided fine-needle aspiration cytology. Tumori 200793 269-274.

86 UNSCEAR. United Nations Scientific Committee on the Effects of Atomic Radiation. 2006 Report to the General Assembly, vol 1, 2006.

87 Brenner DJ, Doll R, Goodhead DT, Hall EJ, Land CE, Little JB, Lubin JH, Preston DL, Preston RJ, Puskin JS, Ron E, Sachs RK, Samet JM, Setlow RB \& Zaider M. Cancer risks attributable to low doses of ionizing radiation: assessing what we really know. PNAS $200310013761-13766$.

88 Cardis E, Vrijheid M, Blettner M, Gilbert E, Hakama M, Hill C, Howe G, Kaldor J, Muirhead CR, Schubauer-Berigan M, Yoshimura T, Bermann F, Cowper G, Fix J, Hacker C, Heinmiller B, Marshall M, Thierry-Chef I, Utterback D, Ahn YO, Amoros E, Ashmore P, Auvinen A, Bae JM, Solano JB, Biau A, Combalot E, Deboodt P, Diez Sacristan A, Eklof M, Engels H, Engholm G, Gulis G, Habib R, Holan K, Hyvonen H, Kerekes A, Kurtinaitis J, Malker H, Martuzzi M, Mastauskas A, Monnet A, 
Moser M, Pearce MS, Richardson DB, Rodriguez-Artalejo F Rogel A, Tardy H, Telle-Lamberton M, Turai I, Usel M \& Veress K. Risk of cancer after low doses of ionising radiation: retrospective cohort study in 15 countries. BMJ 200533177.

89 Kossenko MM, Thomas TL, Akleyev AV, Krestinina LY, Startsev NV Vyushkova OV, Zhidkova CM, Hoffman DA, Preston DL, Davis F \& Ron E. The Techa River Cohort: study design and follow-up methods. Radiation Research 2005164 591-601.

90 Krestinina LY, Preston DL, Ostroumova EV, Degteva MO, Ron E, Vyushkova OV, Startsev NV, Kossenko MM \& Akleyev AV. Protracted radiation exposure and cancer mortality in the Techa River Cohort. Radiation Research 2005164 602-611.

91 Bauer S, Gusev BI, Pivina LM, Apsalikov KN \& Grosche B. Radiation exposure due to local fallout from Soviet atmospheric nuclear weapons testing in Kazakhstan: solid cancer mortality in the Semipalatinsk historical cohort, 1960-1999. Radiation Research 2005164 409-419.
92 Brenner DJ \& Hall EJ. Computed tomography - an increasing source of radiation exposure. New England Journal of Medicine 2007 $3572277-2284$.

93 Ware DE, Huda W, Mergo PJ \& Litwiller AL. Radiation effective doses to patients undergoing abdominal CT examinations. Radiology 1999210 645-650.

94 Martin D \& Semelka R. Health effects of ionizing radiation from diagnostic CT imaging: consideration of alternative imaging strategies. Applied Radiology 200736 20-29.

95 Hidajat N, Maurer J, Schroder RJ, Nunnemann A, Wolf M, Pauli K \& Felix R. Relationships between physical dose quantities and patient dose in CT. British Journal of Radiology 199972 556-561.

Received 14 April 2009

Accepted 5 May 2009 